\title{
Beyond the Technical Skills: A Case for Internationalization of Graduate Attributes in PhD Programs
}

\author{
Rajaraman Eri $^{1, *}$, Prasad Gudimetla ${ }^{2}$, Ravichandra Vemuri ${ }^{1}$ \\ ${ }^{1}$ School of Health Sciences, College of Health and Medicine, University of Tasmania, Australia \\ ${ }^{2}$ School of Engineering and Technology, Bundaberg Campus, CQ University, Australia
}

Copyright $@ 2019$ by authors, all rights reserved. Authors agree that this article remains permanently open access under the terms of the Creative Commons Attribution License 4.0 International License

\begin{abstract}
Internationalization of curriculum (IoC) has garnered momentum, with many universities around the world now viewing graduate students as global citizens. One aspect of IoC that lacks clarity is the students' perception of internationalization of graduate attributes. In this study, we explored graduate student's perceptions of the graduate attributes that need to be included in the curriculum to become internationalized. Advanced stage PhD students $(n=6)$ were interviewed about the relevance of internationalization of specific graduate attributes. A set of six specific questions were posed in the interview that was conducted as a group discussion and was recorded and transcribed. 5 out of 6 students observed that schools, faculties, and universities need to sponsor workshops and seminars regularly which will help students absorb attributes such as cultural and religious tolerance, societal awareness, stress management, building resilience which will help them fit well into any work environment. Another important factor was the need for more exchange programs and conference participation that will expose them to different work environments worldwide and help them recognize how their peers approach similar endeavors. Our study offers insights into what aspects of graduate attributes need to be addressed at the faculty and university levels to promote the IoC.
\end{abstract}

Keywords Internationalization, Graduate Attributes, Soft Skills, Exchange Programs

\section{Introduction: Internationalization of Higher Education}

Internationalization has become an important aspect of higher education in the last decade because of the advances in technology and connectivity throughout the world.
Universities compete to enhance their internationalization portfolio with a view to reap commercial and educational benefits and be prepared for active engagement in a globalized world. Since coined by Peter F. Drucker in 1969, the emergence of global knowledge societies has been considered the 'third industrial revolution' wherein, the creation and application of new knowledge define the pace of advancement and national prosperity. It is within this paradigm that higher educational institutions have acquired a pivotal role in helping synthesize the relationship between higher education and the knowledge society. While the terms are used interchangeably, globalization is the catalyst while internationalization is the response that is promoting the development of higher education in many countries. There is ample statistical evidence of the progressive and sometimes drastic growth in the movement of people across geographical territories in the pursuit of higher education, thereby fuelling both the development of the knowledge society and compelling Universities to embrace internationalization at varying levels. In general, the term" internationalization" often refers to several activities including recruitment of international students, exchange of students and faculty between institutions, activities to build inter-cultural competency and curriculum internationalization.

Knight (2004) defined internationalization as "the process of integrating an international, intercultural or global dimension into the purpose, functions or delivery of post-secondary education” [12]. Clearly, this has placed an additional burden on HE institutions to develop curricula that provide adequate opportunities to enhance not just the academic and professional knowledge but other aspects such as socio-cultural competency, multilingualism, intercultural communication skills and attitudes. Recently, internationalization has emerged as a separate research and policy area for many Universities, as evidenced from journals dedicated to this theme such as JSIE and 
HERDSA, including special issues on internationalization of curriculum (IoC).

\subsection{International PhD Graduates and Internationalization of Curriculum}

Graduate recruitment for Research Higher Degrees (RHD) is now a global process. This has been prompted by the rapid advancement of specialist research areas/domains, the level of financial investment required, and of course, the need for talent pools to form collaborative cooperative international research. The recruitment of international graduates with apt scientific and technical skills has become a significant factor in many ways. Accordingly, to McEwan of University of Queensland (2014), international doctoral students are helping neutralize the low domestic enrolments on the one hand while becoming critical to research output and to forging cost-effective international linkages. They also bring along a wealth of cultural knowledge which is a top transferrable skill that can enhance graduate employability, thereby sustaining long to apply and work in many parts of the world and thus making the graduate employability a globally common theme. In order to rise to this challenge, some Australian universities are already implementing strategies and frameworks that will help nurture such global citizens who can be ready to start their careers in any part of the world.

To address this issue, higher education institutions have been embarking on the Internationalization of Curriculum (IoC). IoC, in its broadest sense, encompasses activities such as study abroad programs, foreign language courses, interdisciplinary or area programs, or the provision of programs or courses with an international, intercultural, or comparative focus [3]. It is now recognized that IoC is an effective means of providing an academic environment that would support diverse cultural learning needs of international students. It is a powerful and practical way of bridging the gap between rhetoric and practice to valuing the contribution of international students [15]. There is a wide body of literature that underscores the importance of IoC in terms of creating an optimal learning environment that reflects diverse cultures, perspectives, and student experiences, since the way people think, reason and interpret knowledge is a function of their social and cultural competencies. Some of these approaches are (1) internationalization of the curriculum by adopting excellent benchmarks in curriculum delivery and curriculum development. In fact, Green and White [5] delved into this issue deeper, and provide some practical solutions including international content in the curriculum, inter-cultural activities and a cosmopolitan campus [18]. (2) Strong international recruitment and utilizing international students to enhance cross-cultural competencies; (3) increased recruitment of internationalized faculty; (1) (4) Specific education involving global managers and recruiters and (5) Offer of joint degrees between international universities. One cohort of students that represent heavily internationalized students are $\mathrm{PhD}$ scholars. Studies indicate that in the majority of institutions in Australia as well as in other parts of the West (USA, UK, and Canada), a large proportion of $\mathrm{PhD}$ students are international. For example, a survey of $\mathrm{PhD}$ student numbers in the USA indicates that over $60 \%$ of $\mathrm{PhD}$ scholars in US Universities are from the non-US background, mainly dominated by students from China and India [20]. In such a background, one unaddressed question in the context of internationalization is: How do we globalize our $\mathrm{PhD}$ programs? What graduate attributes should we expect $\mathrm{PhD}$ programs to develop in order to prepare graduates to live and work in a globalized world? (Do they differ from graduate attributes developed through coursework programs?) In other words, how can we create $\mathrm{PhD}$ scholars who can assimilate in any international setting and be recognized as global citizens?

\section{PhD Graduate Attributes}

The theme of $\mathrm{PhD}$ graduate attributes within the internationalization of education is not well addressed in the Health and Sciences disciplines. On one hand, schools expect $\mathrm{PhD}$ graduates to develop certain graduate attributes at that level but on the other hand, there has to be a delineation of what role the universities can play to enable them to take on international roles in their careers. For example, at the University of South Australia where graduate attributes (developed for coursework students) are exclusively directed at equipping $\mathrm{PhD}$ graduates as global employment ready, Leask (2015a) [14] describes the 7 graduate attributes and amongst those, graduate quality \#7 specifically refers to internationalization as "Demonstrate international perspectives as a professional and as a citizen”. Further expansion of attribute 7 (7.1 to 7.9) exquisitely provides details as to how their graduates can be prepared to face the globalized situation, with a heavy emphasis on cultural competencies. Another excellent example comes from Leeds Metropolitan University curriculum development document [10] where it clearly articulates three important attributes of a globalized graduate namely, knowledge and skills to operate in multicultural contexts, global context, and values of responsible global citizenship.

\subsection{Need for Globalized PhD Graduate Attributes}

According to Bowden and others (2000), graduate attributes should go beyond just the disciplinary expertise or subject knowledge they gain from the university. They should also include certain attributes that address their socio-cultural competencies in a given international setting. Internationalization of $\mathrm{PhD}$ programs is an important aspect of globalized higher education. Firstly, international 
students (in most universities across the western world) form a solid international-link to those institutions. Secondly, in most of these Universities, doctoral students provide critical research support for maintaining quality research work expected of the universities. Obviously, due to these international students, there is the potential to culturally enrich universities. One question that comes forth is - Do these students assimilate the local culture and increase their employability anywhere in the world? Given the situation, there is a need for a uniform internationalized $\mathrm{PhD}$ graduate attributes so that employers can confidently hire these graduates in any part of the world.

Australia produces close to 10,000 higher degree students every year. A survey of recent RHD students (EMCR discussion paper, 2015) suggests that half of these students would like to get into academic jobs while the rest have to find their way into research institutes, industry, pharma, school teaching, and other non-academic positions. Current funding models and support in Australia do not support our $\mathrm{PhD}$ graduates to be job-ready, beyond the academic positions [19]. One major issue then is the preparedness of these $\mathrm{PhD}$ graduates suited for jobs in a multitude of areas, not only in Australia but also overseas. Hence, there is a clear need for developing $\mathrm{PhD}$ graduate attributes that can incorporate 2 important aspects of career development for $\mathrm{PhD}$ graduates. Firstly, a clear strategy about possible career pathways that are available to $\mathrm{PhD}$ graduates and secondly, to quickly integrate and work in any multi-cultural global workplace. A similar anguish was expressed that only a few institutions in the world have specific programs to aid graduate students to develop job-ready international skills such as inter-disciplinary training, inter-organizational training with an international focus and in all of this discussion, graduate student views about internationalization were not clear. To address the specific issue of internationalization of graduate attributes, this study aimed to explore $\mathrm{PhD}$ students' point of view on what they interpret as the link between graduate attributes and internationalization (Ovaska, Asikainen \& Mendoza, 2015) [17].

\section{Methods and Material}

\subsection{Study Design}

A study to investigate the importance of internationalization of $\mathrm{PhD}$ student attributes was undertaken at the School of Health Sciences, University of Tasmania. Six PhD students formed the focus group for the study. These students happened to be in their advanced stages of PhD studies ( $3^{\text {rd }}$ or $4^{\text {th }}$ year) at the School of Health Sciences, Faculty of Health. Invitations were sent to all the 36 students in the discipline of biomedical sciences at the School of Health Sciences and 6 student responses were received within the stipulated period. All 6 students were international students representing 4 different countries (India, Poland, Sri Lanka, and Iran). These students do represent the diverse nature of our international cohort at the School of Health Sciences. Every aspect of the study was approved by the University of Tasmania human ethics committee (approval number H0016927). All participants, mainly in the area of health sciences, attended the semi-structured focus group lasting around one and a half hours. Focus group was facilitated by one of the authors using a set of prompting questions. The following set of questions formed the basis for the focus group interviews.

1. What is the first thing that comes to your mind when we talk about the attributes of a PhD student?

2. Can you share how your thoughts on what attributes are required of a $\mathrm{PhD}$ student aiming to be an internationalized $\mathrm{PhD}$ student?

3. Do you believe you are ready to work in any part of the world? If so, why? If not, why not?

4. Would the employability of $\mathrm{PhD}$ graduates increase if they are provided with specific attributes aimed at internationalization?

5. What can be done to improve current PhD student attributes to include internationalization?

6. Is there value in including aspects of internationalization in the curriculum?

Each of the above questions was put the group and every student got an opportunity to provide their individual answers. Following this, there was an open discussion which provided all the participants an opportunity to further qualify or add to their previous views. Finally, each participant was asked to provide a one-line summary of what they felt was perhaps the most important aspect that will help them internationalized.

The interviews and discussion spanned for over an hour. The entire focus group discussion was recorded and transcribed using a professional transcription service. The transcript formed the major document for data analysis. Both the authors studied the transcript in detail and formed major themes. The thematic analysis was further expanded by repeated discussions and further clarifications from the students, where needed.

\section{Results}

\subsection{Analysis of Focus Group Responses}

The authors each listened to the recording individually and carried out a two-step analysis. First, each candidate's response for each question was heard and a set of common words and phrases were identified. These common words/phrases were then used to create distinct themes. A total of seven themes were thus created as below:

1. Soft skills

2. Technical skills

3. Ethics, Code of Practice and Operating Procedures 


\section{Cultural Sensitivity and Religious Tolerance \\ 5. Social and Geopolitical Awareness \\ 6. Personal disposition \\ 7. University Sponsorship}

1. Soft skills - $100 \%$ of the cohort placed a lot of emphasis on communication skills. All the students felt that if their technical/scientific persona is well developed and recognized, they would be able to effectively communicate with their peers and colleagues to share their ideas and perspectives and thus, be able to market themselves (employability). Some identified language as the main barrier in trying to develop robust networks.

2. Technical skills - 5/6 of the participants expressed the need to partake ad hoc workshops/training that can help brush up their technical skills which could be used as further credits in their CVs. They could be allowed to design and run experiments with minimum supervision which would instill a lot of confidence about laboratory procedures and conduct. This would thus be able to convince their prospective employer about their ability to use state-of-the-art scientific equipment in any/different settings.

3. Ethics, Code of Practice and Operating Procedures All the 6 participants said that it is imperative to become knowledgeable of the codes of practice and standard operating procedures in different settings across the world but they do not readily have access to such information and need to make special personal efforts to educate themselves on such aspects.

4. Cultural Sensitivity and Religious Tolerance - this aspect again was given high importance by the entire cohort, with one student stating that 'respect and empathy towards the individual supersede everything else. If these qualities are nurtured, then the person can flourish in any setting.' Along similar lines, some opined that $\mathrm{PhD}$ graduates must develop cultural awareness and be appreciative and receptive to events around them. They said that there was no specific training provided which addressed this aspect, such as learning a new language. One other participant stated that it was only after their move to Australia that they got exposure to different religions and it took them some time to come to terms with such multicultural aspects.

5. Social and Geopolitical Awareness - This was another theme that was highlighted by half of the participants. They felt that social awareness would give them an edge to better prepare themselves to pursue their careers in different regions. In a similar vein, it is imperative that they follow the local economic situation and changes which may have an influence on their careers and help them make the right decisions.

6. Personal Disposition - all participants stressed the role of various personal traits that form important attributes of their functionality and success. These included punctuality, good organizational skills, efficient time and resource management, ability to work under minimum supervision, ability to manage stress and work for long hours to meet deadlines, maintain cordial work relationships with colleagues and peers, and be polite and understanding.

7. University Sponsorship- 5/6 participants underscored the need for several university and faculty level initiatives that could help them develop many of the attributes. For example, some felt that there is an opportunity for Universities to collaborate with other top Universities and Research Centres and institute exchange programs which will help graduate students to visit such centers and acquire valuable experience. More travel scholarships and short-stay bursaries could be offered with reciprocal arrangements that will entail immense skills and knowledge transfer.

\section{Discussion}

This study aimed to define internationalization of graduate attributes as expressed by $\mathrm{PhD}$ students. Based on focus group discussions, 4 major themes have emerged. Firstly, all the students agreed that one key student attribute that is extremely vital as a graduate attribute is a communication. In fact, most students linked communication skills to job readiness and employment. Further, an interesting aspect is that there is a clear link between international student exchanges/conference attendances which in turn leads to improvements in communication skills. The major discussion point from all student about internationalization was about the possibility of undertaking exchange programs or attending multiple international conferences. Further, undertaking some work outside their country was seen as important aspects of internationalization of $\mathrm{PhD}$ graduate attributes. Interestingly, it was also felt that the above-mentioned aspects could be included in the curriculum and if possible, even as a module in a $\mathrm{PhD}$ program. As described by Lightfoot and Lee (2015), student exposure to short-term international experiences is ideal because such experiences cause minimal disruption to their work and life yet provide excellent international experience [15]. It has to be acknowledged that the significance of short-term international experience is a hotly debated area. On the other hand, researchers Appadurai [1] and Barnett [2] argue that the educational institutions preparing students for specific jobs are ill-conceived. Jones and authors [7] while comparing discipline-specific graduate attributes in 5 faculties including history, physics, and medicine, explains the status as highly context-dependent skills and proposes instead a re-disciplined generic skill for graduates. According to the Open Doors report (2016) [6], only around 1 in 10 doctoral level program students in the USA get to experience study abroad. Data from Australia is also likely to be very similar to the US data (Okahana \& Allum, 2015). It is thus very clear that some more attention needs to be provided to exchange programs for $\mathrm{PhD}$ students 
[16].

Employability has become an important aspect of international education, with Universities and Government agencies pushing for improvements in employability and job-readiness of graduates. Apart from the discussion described above, all students described that their employability will be enhanced by some international exposure during their $\mathrm{PhD}$ tenure.

To the question of cultural competency, it was extremely surprising to note that the students did not attach extreme importance to inter-cultural competence as an attribute for internationalization of graduate attribute. It was striking to note that there was no specific mention of training in cultural competency. In fact, many felt that solid work ethics and working in cultural groups would be sufficient to attain cultural competency. Several studies also indicate that students placed in multi-cultural groups are likely to benefit, as such a set-up increases their cultural competency. Author Killick mentioned [10], while providing guidelines for graduate attributes for Leeds Metropolitan University, proposes knowledge, awareness, values, and skills in multicultural contexts. In fact, a recent study by Clifford and group [4] support the view expressed by students here by explaining that intercultural competence doesn't need to be to the level of major changes to programs but identify a definite need for changes to the curriculum with respect to internationalization.

Jones and Killick describe "Global Outlook" as one major attribute for internationalization of curriculum [8]. This attribute defined as "enabling effective and responsible engagement in a multicultural and globalizing world" relates to inclusivity, diversity with global relevance. From this study, one can assign increased exposure to international work experience to the aspect of the global outlook. Advanced Wastewater Management center at the University of Queensland lists graduate attributes as skills in problem-solving, communication, project management, industry/professional experience, understanding and applying international perspectives [9] similar the outcome of this focus group discussion.

\section{Salient Findings of the Study}

Participants in this study indicated that developing cultural competency is very important to successful association and functioning in an international setting. It is imperative that we respect other peoples' culture, religion, beliefs, and values. On the other hand, such attitude will instill respect for others' views/perspectives and pave way for mutual success.

Participants recognized that supervisors at the local level have a major role to play in Internationalization of the curricula: 1) they should effectively manage students from different backgrounds and establishing good communication frameworks and help them interact with each other. 2) Organize periodic communal workshops, discussion forums etc., within the research centre to foster and share research ideas and perspectives. Students should also be encouraged to attend such events hosted by other research centers either within the same faculty or elsewhere within the university. 3) Supervisors should communicate with their peers and arrange for as many reciprocal visiting events as possible. This will provide students with excellent opportunities to interact with peers and researchers from other countries and backgrounds and exchange a whole gamut of knowledge and information. 4) They should organize and promote regular seminars, talks, and discourses by inviting top researchers and attendance to such events should be made mandatory and count towards some form of credit in the program and finally. 5) Supervisors should recommend and include more conference travel which will help students network and familiarise themselves with different parts of the world.

From a wider aspect, some students said that better and enhanced administrative support is needed from the University that will smoothen many operational issues that students currently face. This is in terms of applying for scholarships and grants. There is an opportunity to organize 'job fairs' and invite industry stakeholders who could share a lot of information about possible career pathways to an otherwise introspected PhD student. Such events will help disseminate useful information to students who can make better and more informed choices.

Students opined that many of the above activities could be embedded within their $\mathrm{PhD}$ programs which will help instill such desired graduate capabilities uniformly within a cohort and no one would feel isolated at any stage of their candidatures. This is particularly important while trying to develop effective communication skills. Mandatory workshops on technical and scientific writing would help students also navigate more efficiently through their candidatures by developing better theses and thereby, reducing the workload of supervisors in terms of reviewing and editing such works.

\section{Conclusions}

Our focus group study described here has some interesting and to some extent surprising findings. Advanced stage $\mathrm{PhD}$ scholars interviewed seem to favor a model of internationalization of graduate attributes that include communication skills development on top of the list, while inter-cultural competence is seen as an attribute that will develop over time with students from a different background working together, without a need for any specific training. Interestingly, one of the important attributes for internationalization is the ability for $\mathrm{PhD}$ students to be part of international exchange programs and the consensus favors an active program aimed at that area. 
In fact, students from this study link their experience away from their place of study as an international experience to job readiness. However given the very small sample size from one disciplinary group, it is best to consider this as a pilot study that has raised some important questions for further research so as to include a wider cohort from other disciplines.

\section{Disclosure Statement}

No potential conflict of interest reported by the authors.

\section{REFERENCES}

[1] A. Appadurai. Disjuncture and difference in the global cultural economy. Theory, culture \& society. 1990, 7, 295-310.

[2] R. Barnett. University knowledge in an age of super complexity. Higher education, 2000, 40, 409-422.

[3] L. Bremer, M, Van Der Wende. Internationalising the Curriculum in Higher Education: Experiences in the Netherlands. The Hague: The Netherlands Organisation for International Cooperation in Higher Education. Sheffield Hallam University in July 1999]. Sheffield Hallam University Press, 2000.

[4] V. Clifford, C. Montgomery. Designing an internationalized curriculum for higher education: embracing the local and the global citizen. Higher Education Research \& Development, 2017, 36, 1138-1151.

[5] Fischer S, Green W. Understanding contextual layers of policy and motivations for internationalization: Identifying connections and tensions. Journal of Studies in International Education. 2018 22(3):242-58.

[6] Institute of International Education (IIE). Open Doors Report for 2016. Retrieved fromhttps://www.iie.org/Resear ch-and-Insights/Open-Doors/Data/US-Study-Abroad/Stude nt-Profile (accessed on 31 October 2018).

[7] Jones, A. Redisciplining generic attributes: The disciplinary context in focus. Studies in Higher Education, 2009, 34, 85-100.

[8] Jones, E.; Killick D. Graduate attributes and the internationalized curriculum: Embedding a global outlook in disciplinary learning outcomes. Journal of Studies in International Education, 2013, 17, 165-182.

[9] Kiley, M., \& Mullins, G. (Eds.). Quality in postgraduate research: Re-imagining research education. Proceedings of the 2004 international quality in Postgraduate Research Conference, Adelaide, Australia, 2004.

[10] Killick, D. Cross-cultural capability and global perspectives. Guidelines for curriculum review, leeds: Leeds Metropolitan University, 2006. Retrieved from www.leedsmet.ac.uk/international/Cross Cultul Capability Guidelines.pdf. (accessed on 31 October 2018).
[11] Killick, D. Cross-Cultural Capability \& Global Perspectives Guidelines for Curriculum Review, 2005; Leeds Met Press.

[12] Knight, J. (2004). Internationalization remodeled: Definition, approaches, and rationales. Journal of studies in international education, 2004, 8, 5-31.

[13] Leask, B. Internationalisation of the curriculum and intercultural engagement - a variety of perspectives and possibilities. Refereed paper presented at the Australian International Education Gold Coast, Qld, 2005.

[14] Leask, B. Graduate capabilities, global citizenship and intercultural competency. In B. Leask, Internationalizing the curriculum 2015; 53-67. London: Routledge.

[15] Lightfoot, E.; Lee, H. (2015). Professional international service learning as an international service learning opportunity appropriate for graduate or professional students. The International Education Journal: Comparative Perspectives, 2015, 14, 32-41.

[16] Okahana, H.; Allum, J. International graduate applications and enrollment: Fall 2015. Washington, DC: Council of Graduate Schools. Retrieved from http://cgsnet.org/ckfinde r/userfiles/files/2015_International_Graduate_Admissions \%20Survey_FINAL.pdf (accessed on 21 October 2018).

[17] Ovaska, Milla. Asikainen, Milja.; Mendoza, Carlos. (2015). Aalto is Multicultural. Retrieved from https://ayy.fi/en/stud ents/international-ayy/multicultural-aalto/ (accessed on 3 October 2018).

[18] Rizvi, F. International education and the production of cosmopolitan identities In A. Arimato, F. Huang, K.Yokoyama, \& D. Hiroshima (Eds.), Globalization and higher education. Hiroshima, Japan: Research Institute of Higher Education, 2005.

[19] Online Available: The Group of Eight (Go8) (2013). Retrieved from https://go8.edu.au/sites/default/files/docs/th e-changing-phd_final.pdf. (accessed on 31 October 2018).

[20] Online Available: U.S council of Graduate schools (2016). Retrieved form http://cgsnet.org/2016-reports (accessed on 31 October 2018). 